\title{
VARIABILIDAD GENÉTICA DE CEPAS DE Gallibacterium anatis AISLADAS DE AVES COMERCIALES DEL PERÚ CON INFECCIONES RESPIRATORIAS
}

\author{
GENETIC VARIABILITY OF Gallibacterium anatis STRAInS ISOLATED FROM \\ Peruvian Commercial Birds with Respiratory Infections
}

\author{
Karina Mendoza A., ${ }^{1,3}$, Amparo I. Zavaleta ${ }^{2}$, Ysabel Koga ${ }^{1}$, Jorge Rodríguez B. ${ }^{1}$, \\ Arnaldo Alvarado S. ${ }^{1}$, Robert Tinoco R. ${ }^{1}$
}

\section{Resumen}

El propósito del estudio fue determinar la variabilidad genética de 96 cepas de Gallibacterium anatis aisladas de aves comerciales con sintomatología respiratoria, provenientes de Arequipa (2), Ica (3), La Libertad (27), Lima (62), Madre de Dios (1) y Ucayali (1), y recolectadas desde el 2007 al 2011. Las cepas se tipificaron mediante pruebas de fermentación de carbohidratos y sensibilidad a nueve antimicrobianos. La variabilidad genética de las cepas de $G$. anatis se determinó mediante ERIC-PCR, previa identificación por PCR usando cebadores específicos. Del análisis de fermentación de carbohidratos se obtuvieron perfiles que correspondieron a 10 biovares, todos los cuales se encontraron en Lima y el $45.8 \%$ de las cepas pertenecieron al biovar 4 . Con respecto a la sensibilidad antimicrobiana, el $40.8 \%$ de las cepas fueron resistentes a todos los antimicrobianos estudiados, en tanto que el 94.8 y $95.8 \%$ fueron resistentes a enrofloxacina y ciprofloxacina. Por ERIC-PCR se obtuvieron 24 perfiles de ADN no asociados con los biovares, lo cual indica la existencia de variabilidad genética intraespecífica en cepas de G. anatis circulantes en Perú.

Palabras clave: variabilidad genética, Gallibacterium anatis, aves comerciales, ERICPCR, biovares, Perú

\footnotetext{
${ }^{1}$ Bioservice SRL, Lima

${ }^{2}$ Laboratorio de Biología Molecular, Facultad de Farmacia y Bioquímica, Universidad Nacional Mayor de San Marcos, Lima

${ }^{3}$ E-mail: karina604@hotmail.com
}

Recibido: 12 de abril de 2013

Aceptado para publicación: 4 de enero de 2014 
The purpose of this study was to determine the genetic variability of strains of Gallibacterium anatis isolated in commercial poultry with respiratory symptoms from Arequipa (2), Ica (3), La Libertad (27), Lima (62), Madre de Dios (1) and Ucayali (1), collected from 2007 to 2011. Strains were typified by carbohydrate fermentation tests and sensitivity to nine antimicrobials. The genetic variability of these strains was determined by ERIC-PCR, after identification by PCR using specific primers. The analysis of carbohydrate fermentation profiles corresponded to 10 biovars, all of which were found in Lima and $45.8 \%$ of the strains belonged to biovar 4 . Concerning antimicrobial susceptibility, $40.8 \%$ of strains were resistant to all antimicrobials studied, while 94.8 and 95.8\% were resistant to enrofloxacin and ciprofloxacin. By ERIC-PCR 24 DNA profiles associated with biovars were obtained, indicating the existence of intraspecific genetic variability in strains of $G$. anatis circulating in Peru.

Key words: genetic variability, Gallibacterium anatis, commercial poultry, ERIC-PCR, biovar, Peru

\section{INTRODUCCIÓN}

En el sector avícola, las enfermedades infecciosas, principalmente las del sistema respiratorio, representan uno de los mayores problemas de sanidad animal con niveles de morbilidad y mortalidad entre 10 y $50 \%$ (León, 2009).

En aves comerciales, las enfermedades respiratorias se pueden clasificar en virales y bacterianas. Dentro de los agentes virales destacan Paramoxovirus, Coronavirus, Herpesvirus, Metapneumovirus y en las bacterianas se describen Avibacterium paragallinarum, Ornithobacterium rhinotracheale, Pasteurella multocida, Gallibacterium anatis y Escherichia coli (agente oportunista), entre otras (Vadillo et al., 2002).

Estos agentes infecciosos ocasionan signos clínicos comunes tales como fluido óculo nasal, ojos con aspecto almendrado, conjuntivitis y edema facial e intermandibular o hipertrofia de senos infraorbitarios, los cuales dificultan la identificación del agente patógeno responsable (Bojesen et al., 2004; Bisgaard et al., 2005; Blackall et al., 2005; García-Gómez, 2005; Leon, 2009; García, 2010).

Gallibacterium anatis es un cocobacilo Gram negativo, que se aísla de muestras clínicas de aves con infecciones respiratorias. El mayor número de casos de G. anatis procede de Dinamarca y Alemania (Christensen et al., 2003). En Perú no existe un estudio sistematizado de las cepas y de los biovares circulantes que afectan a las aves comerciales.

El estudio del mapa epidemiológico de G. anatis y de nuevas técnicas diagnósticas para su caracterización puede permitir elaborar programas efectivos de sanidad aviar, en los cuales se consideren cepas endémicas de las principales zonas de producción avícola de Perú. Por ello, el objetivo del presente trabajo fue determinar la variabilidad genética de cepas de G. anatis aisladas de aves comerciales con infecciones respiratorias. 


\section{MaTeRIALES Y Métodos}

\section{Cepas bacterianas}

Se utilizaron 96 cepas de G. anatis aisladas de muestras clínicas de pollos de carne $(n=38)$, gallinas de postura $(n=37)$ y reproductoras $(n=19)$, y gallos de pelea $(n=2)$ con enfermedades respiratorias. Los pollos tenían entre 20 a 50 días, las gallinas de postura entre 6 y 50 semanas y las reproductoras entre 13 y 35 semanas. Las muestras fueron recolectadas desde el 2007 al 2011 de granjas de Arequipa (2), Ica (3), La Libertad (27), Lima (62), Madre de Dios (1) y Ucayali (1). Las cepas fueron guardadas en glicerol a $-20{ }^{\circ} \mathrm{C}$ y liofilizadas. Además, se utilizaron cepas como control positivo de G. anatis ATCC 542 y como controles negativo de Pasteurella multocida y Ornithobacterium rhinotraquealle.

\section{Cultivo de $G$ anatis}

Las cepas liofilizadas de G. anatis fueron hidratadas con $2 \mathrm{ml}$ de caldo cerebro corazón e incubadas a $37^{\circ} \mathrm{C}$ por $24 \mathrm{~h}$. Después se sembraron en agar sangre de ovino al $5 \%$ (utilizando campanas de microaerobiosis) y se incubaron a $37^{\circ} \mathrm{C}$ por 24 a $48 \mathrm{~h}$.

\section{Prueba de Fermentación de Carbohi- dratos}

Se prepararon $100 \mathrm{~mL}$ del medio basal conteniendo peptona $1 \mathrm{~g}, \mathrm{NaCl} 0.5 \mathrm{~g}$, púrpura de bromocresol $1 \% 0.5 \mathrm{ml} \mathrm{a} \mathrm{pH} 6.8$, y se autoclavó a $121{ }^{\circ} \mathrm{C}$ por $15 \mathrm{~min}$. Paralelamente, se prepararon soluciones acuosas al $20 \%$ de cada uno de los siguientes carbohidratos: arabinosa, xilosa, inositol, sorbitol, maltosa, trealosa y dextrina. Las soluciones se esterilizaron por filtración en membranas de acetato de celulosa $0.22 \mu \mathrm{m}$ y se conservaron en congelación.

Una colonia de cada cepa bacteriana se sembró en $2 \mathrm{~mL}$ de caldo nutritivo en las mismas condiciones de cultivo de $G$. anatis antes descritas. Para cada cepa se utilizaron siete microtubos estériles. A cada uno se le agregó $200 \mu \mathrm{L}$ del medio basal, $10 \mu \mathrm{L}$ del carbohidrato a analizar y $10 \mu \mathrm{L}$ del inóculo. Adicionalmente, se utilizó un microtubo con medio basal sin inóculo. Los microtubos fueron colocados sobre papel toalla humedecido con agua destilada estéril dentro de una bolsa plástica transparente, y se incubaron a $37^{\circ} \mathrm{C}$ de 24 a 48 horas. La reacción se consideró positiva si la solución se tornó amarilla y negativa si fue púrpura.

Las cepas de G. anatis se tipificaron en biovariedades de acuerdo al perfil de fermentación de los carbohidratos descrito en el Cuadro 1.

\section{Sensibilidad Antimicrobiana}

Se realizó un antibiograma a cada cepa por el método de difusión en agar sangre al 5\% usando discos de nueve antimicrobianos: florfenicol $30 \mu \mathrm{g}$, fosfomicina $50 \mu \mathrm{g}$, amoxicilina $20 \mu \mathrm{g}$, ciprofloxacina $5 \mu \mathrm{g}$, enrofloxacina $5 \mu \mathrm{g}$, doxicilina $30 \mu \mathrm{g}$, norfloxacina $10 \mu \mathrm{g}$, espectinomicina $100 \mu \mathrm{g}$, sulfatrimetropin $1.25 / 23.75 \mu \mathrm{g}$.

Las placas de agar sangre fueron preparadas con el inóculo y los antimicrobianos se incubaron a $37^{\circ} \mathrm{C}$ de 24 a $48 \mathrm{~h}$. Se midió el halo de inhibición del crecimiento alrededor de los discos, asignando la condición de sensible, intermedio o resistente, según NCCLS (National Conmittee for Clinical Laboratory Standards, 1993).

\section{Extracción del ADN Genómico}

Las cepas liofilizadas fueron reactivadas con caldo nutritivo y sembradas en agar sangre a $37^{\circ} \mathrm{C}$ por $24 \mathrm{~h}$. El ADN genómico fue extraído utilizando el Wizard® Genomic DNA Purification Kit (Promega, EEUU), siguiendo el procedimiento descrito por el fabricante. El ADN extraído se observó por electroforesis en gel de agarosa al $1 \%$ en buffer TBE (Tris, Borato, EDTA) 0.5X, tiñéndose con bromuro de etidio $(0.5 \mu \mathrm{g} / \mathrm{ml})$ 
Cuadro 1. Pruebas bioquímicas para identificar biovares de Gallibacterium anatis

\begin{tabular}{|c|c|c|c|c|c|c|c|}
\hline \multirow[b]{2}{*}{ Biovar } & \multicolumn{7}{|c|}{ Características bioquímicas de los biovares ${ }^{1}$} \\
\hline & $\begin{array}{c}\text { (+) L- } \\
\text { arabinosa }\end{array}$ & $\begin{array}{l}\text { (+) D- } \\
\text { xilosa }\end{array}$ & $\begin{array}{c}\mathrm{m}- \\
\text { inositol }\end{array}$ & $\begin{array}{c}(-) \mathrm{D}- \\
\text { sorbitol }\end{array}$ & Maltosa & Trehalosa & Dex trina \\
\hline 1 & - & $+/(+)$ & $+/(+)$ & + & + & $+/(+)$ & $+/(+)$ \\
\hline 2 & - & + & + & + & + & + & - \\
\hline 3 & - & + & $+/(+)$ & + & + & - & + \\
\hline 4 & - & + & $+/(+)$ & + & - & $+/(+)$ & $-/(+)$ \\
\hline 5 & - & + & - & - & + & + & $(+)$ \\
\hline 6 & - & + & - & + & + & + & + \\
\hline 7 & - & - & $(+)$ & + & + & + & + \\
\hline 8 & + & + & - & - & + & + & + \\
\hline 9 & - & + & $+/(+)$ & - & + & - & + \\
\hline 10 & - & + & - & + & + & + & - \\
\hline 11 & - & + & + & + & - & - & $-/(+)$ \\
\hline 12 & - & + & $+/(+)$ & - & - & $+/(+)$ & $-/(+)$ \\
\hline 13 & - & + & - & + & - & + & - \\
\hline 14 & - & - & + & + & + & - & - \\
\hline 15 & - & - & + & + & - & - & - \\
\hline 16 & - & - & - & + & - & + & - \\
\hline 17 & - & + & $+/(+)$ & - & - & - & - \\
\hline 18 & - & + & - & - & - & $+/(+)$ & $-/(+)$ \\
\hline 19 & - & + & - & - & - & - & - \\
\hline 20 & - & - & - & - & - & + & - \\
\hline 21 & - & - & + & - & - & - & - \\
\hline 22 & - & + & - & + & - & - & - \\
\hline 23 & - & - & - & - & + & + & + \\
\hline 24 & - & $+/(+)$ & $+/(+)$ & - & + & + & $+/(+)$ \\
\hline
\end{tabular}

y observándose en un transiluminador (Biometra UVstar 312 nm, Alemania) de luz ultravioleta.

\section{PCR (Reacción en Cadena de la Polime- rasa)}

Se usaron los cebadores descritos por Bojesen et al. (2007), los cuales fueron diseñados a partir de las secuencias de los genes ribosómicos $16 \mathrm{~S}$ y $23 \mathrm{~S}$ de G. anatis.
La mezcla de reacción fue de $20 \mu 1$, la cual contenía buffer PCR 1X, $0.2 \mathrm{mM}$ de cada dNTP, $\mathrm{MgCl}_{2} 1.5 \mathrm{mM}, 5$ pmol de cada cebador (114R 5'-GGT TTCCCCATTCGG3' y 133Fgal 5'-TATTCTTTGTTACCACCGG- 3'), Ampli Taq 1 U de ADN polimerasa y $30 \mathrm{ng}$ de ADN genómico. La reacción se realizó en un termociclador Veriti Thermal Cycler (Applied Biosystems, Veriti ${ }^{\circledR}$ 96-Well, EEUU) bajo las siguientes condiciones: desnaturalización inicial a $95{ }^{\circ} \mathrm{C}$ por 5 
min, 35 ciclos de desnaturalización a $94{ }^{\circ} \mathrm{C}$ por $30 \mathrm{~s}$, alineación a $55^{\circ} \mathrm{C}$ por $1 \mathrm{~min}$, extensión a $72^{\circ} \mathrm{C}$ por $2 \mathrm{~min}$, y una extensión final a $72{ }^{\circ} \mathrm{C}$ por $10 \mathrm{~min}$.

Los productos de PCR se separaron por electroforesis en gel de agarosa $1 \%$ en buffer TBE $0.5 \mathrm{X}$, tiñéndose con bromuro de etidio $(0.5 \mu \mathrm{g} / \mathrm{ml})$.

\section{Reacción ERIC-PCR (Enterobacterial Repetitive Intergenic Consensus - PCR)}

Se empleó una mezcla de reacción de $20 \mu \mathrm{L}$, que contenía buffer PCR 1X, $0.2 \mathrm{mM}$ de cada dNTP, $\mathrm{MgCl}_{2} 3.5 \mathrm{mM}, 10$ pmol de cada cebador (ERIC1R 5'-ATGTAAGCTCCTGGGGATTCAC-3' y ERIC2 5'AAGTAAGTGACTGGGGTGAGCG-3’) descritos por Leotta et al. (2006), $2 \mathrm{U}$ de Ampli Taq ADN polimerasa y $30 \mu \mathrm{g}$ de ADN genómico. La reacción se realizó en el termociclador antes indicado bajo las siguientes condiciones: desnaturalización inicial a $95^{\circ} \mathrm{C}$ por $3 \mathrm{~min}, 35$ ciclos de desnaturalización a $94{ }^{\circ} \mathrm{C}$ por $30 \mathrm{~s}$, alineación a $40{ }^{\circ} \mathrm{C}$ por 3 min, extensión a $72{ }^{\circ} \mathrm{C}$ por 2 min, y una extensión final a $72{ }^{\circ} \mathrm{C}$ por $7 \mathrm{~min}$.

Los productos de PCR se separaron por electroforesis en gel de agarosa al $1 \%$ en buffer TBE $0.5 X$. Para la comparación de los tamaños de las bandas se utilizó Ladder 100 bp-Plus (Fermentas, EEUU).

\section{Análisis de Patrones de ADN}

Los patrones de ADN obtenidos por ERIC-PCR se analizaron con el programa Biodoc Analyze v2.2 (Biometra). Luego, se transformaron a una matriz bidimensional utilizando el coeficiente de Jaccard y Dice mediante el programa FAMD v1.25 (Schlüter, 2006). La variabilidad genética intraespecífica de las 96 cepas de G. anatis fue analizada con el programa AMOVA en base a una matriz de distancia genética y se generaron dendrogramas de similitud mediante el método UPGMA usando los programas FAMD v1.25 y Mega v5.0 (Tamura et al., 2011).

\section{Resultados}

El 28.4 y $64.2 \%$ de las cepas de $G$. anatis aisladas de aves comerciales procedían de los departamentos de La Libertad y Lima, zonas del país con la mayor población de aves comerciales. Asimismo, el 40\% de cepas fueron aisladas de pollos de carne y el $38 \%$ de gallinas ponedoras (Fig. 1). En agar sangre de ovino, el $80 \%$ de las cepas de $G$. anatis mostraron hemólisis débil y el restante $20 \%$ presentó hemólisis intensa, siendo esta última, una característica de cepas que se diseminan a varios órganos.

En la clasificación de las cepas en biovares, mediante el perfil de hidrólisis a azúcares, se observaron 10 biovares, siendo el biovar 4 el de mayor frecuencia con el $46 \%$ de las cepas. Además, se encontró un biovar nuevo (NI) que agrupa al 6\% $(\mathrm{n}=6)$ de cepas de G. anatis y cuya característica fue la fermentación positiva de todos los azúcares analizados (Fig. 2).

En el Cuadro 2 se observa que los 10 biovares de $G$. anatis están distribuidos en las 62 cepas procedentes de Lima. Además, el biovar 4 se encuentra en cepas de Ica, La Libertad y Arequipa. Por otro lado, el biovar NI está disperso en La Libertad, Lima y Ucayali.

Las 96 cepas fueron confirmadas como G. anatis mediante PCR usando cebadores específicos. Los productos amplificados fueron tres fragmentos de ADN de 1032, $985 \mathrm{y}$ 789 pb. Asimismo, se evidenció que los cebadores hibridan con P. multocida y $O$. rhinotracheale, especies filogenéticamente relacionadas con $G$. anatis, pero producen un fragmento de ADN mayor a 1400 pb (Fig. 3).

En el análisis de la variabilidad genética intraespecífica usando la técnica ERIC-PCR se obtuvieron 20 fragmentos de ADN diferentes cuyos tamaños están entre 100 a 1500 $\mathrm{pb}$. El mayor número de fragmentos de ADN polimórficos (11 bandas) se encontró en las cepas de G. anatis pertenecientes al biovar 3 ; sin embargo, no se encontraron bandas en 

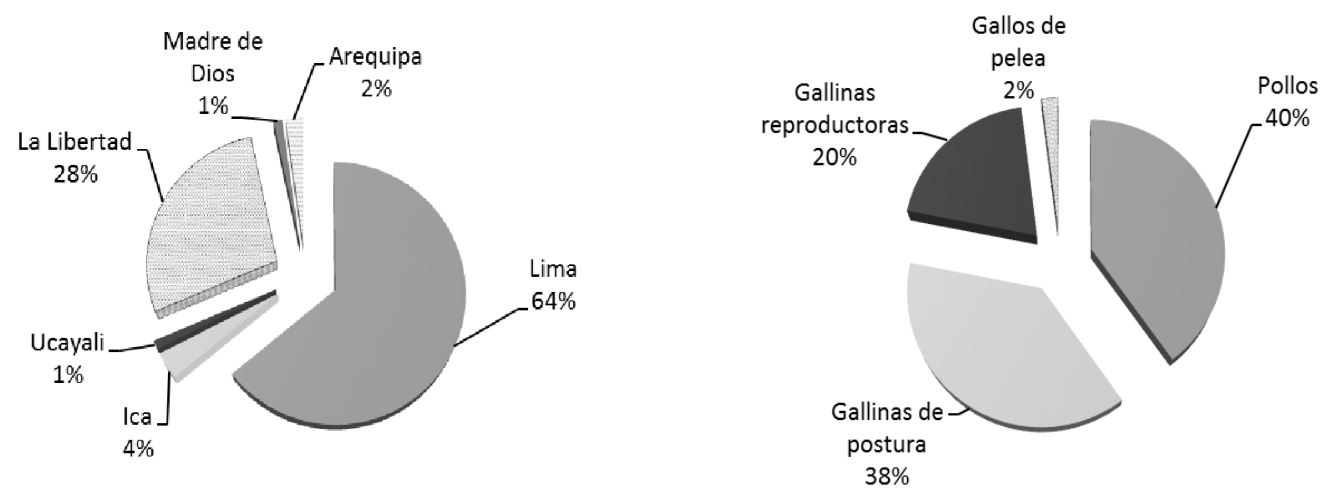

Figura 1. Frecuencia porcentual de cepas de Gallibacterium anatis, según localización geográfica (lado izquierdo) y tipo de ave (lado derecho)

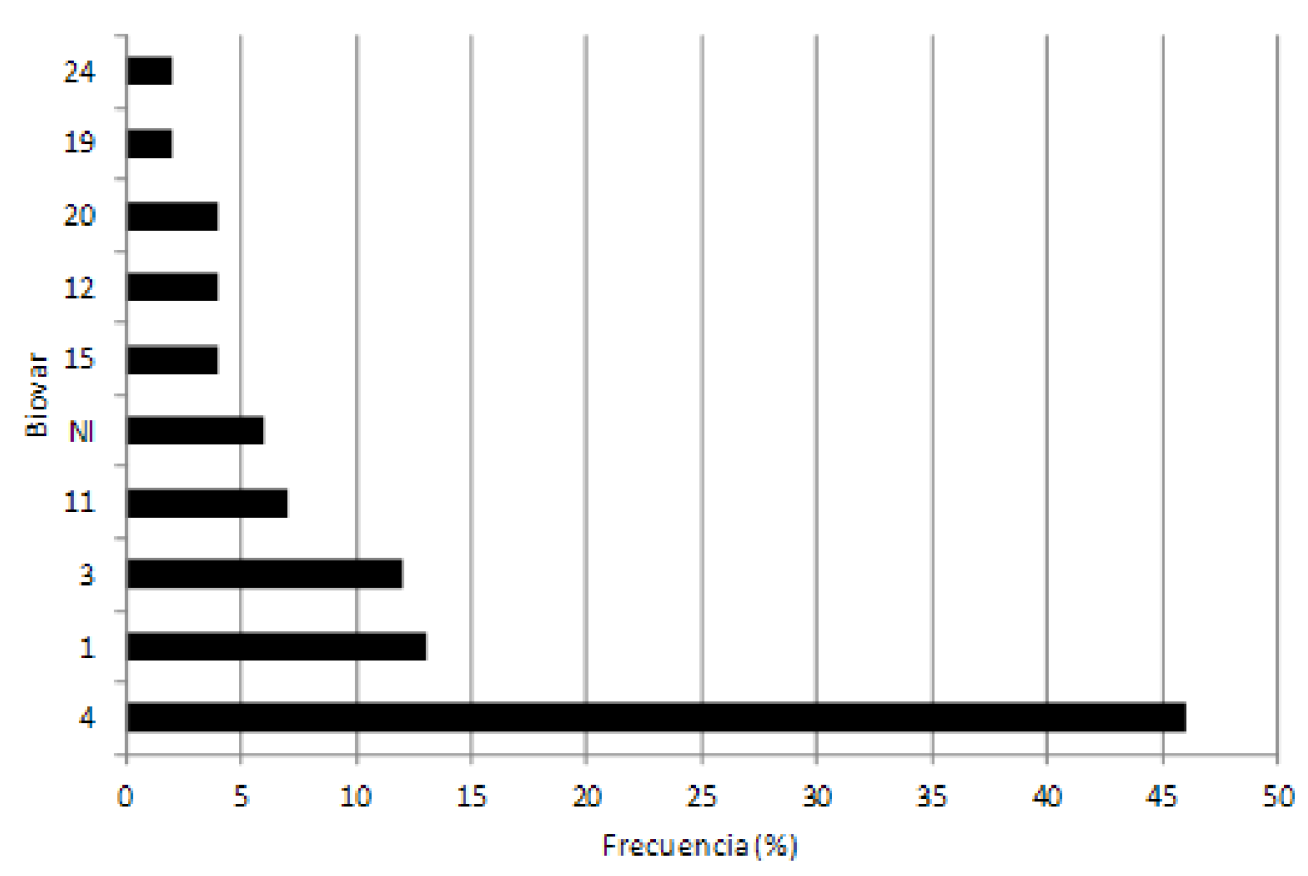

Figura 2. Frecuencia porcentual de cepas de Gallibacterium anatis aisladas de aves comerciales del Perú con infecciones respiratorias, según el biovar 
Cuadro 2. Número de aislados y de biovares de Gallibacterium anatis obtenidos de aves comerciales del Perú con infecciones respiratorias, según origen de procedencia de la muestra

\begin{tabular}{lcl}
\hline Departamento & $\begin{array}{c}\text { Aislados } \\
(\mathrm{n})\end{array}$ & Biovar \\
\hline Lima & 62 & $1,3,4,11,12,15,19,20,24 . \mathrm{NI}^{1}$ \\
Ica & 3 & 1,4 \\
Ucayali & 1 & $\mathrm{NI}^{1}$ \\
La Libertad & 27 & $1,3,4,11,12,15,20,24, \mathrm{NI}$ \\
Madre de Dios & 1 & 11 \\
Arequipa & 2 & 4 \\
\hline
\end{tabular}

${ }^{1}$ Biovar no identificado, no descrito

Cuadro 3. Sensibilidad antimicrobiana porcentual de cepas de Gallibacterium anatis aisladas de aves comerciales del Perú con infecciones respiratorias

\begin{tabular}{lccc}
\hline Antimicrobiano & Sensibles & Intermedias & Resistentes \\
\hline Florfenicol & 49.0 & 6.3 & 44.8 \\
Fosfomicina & 51.0 & 8.3 & 40.6 \\
Amoxicilina & 42.7 & 5.2 & 52.1 \\
Ciprofloxacina & 3.1 & 1.0 & 95.8 \\
Enrofloxacina & 4.2 & 1.0 & 94.8 \\
Doxiciclina & 4.2 & 1.0 & 94.8 \\
Norfloxacina & 1.0 & 0 & 80.2 \\
Espectinomicina & 17.7 & 2.1 & 80.2 \\
Sulfatrimetroprin & 2.1 & 0 & 97.9 \\
\hline
\end{tabular}

los biovares 12 y 19 . Además, no se observaron bandas específicas para cada biovar, a excepción del biovar 3 (1 banda). Se obtuvieron 24 patrones o perfiles diferenciados de las 96 cepas de $G$. anatis. La frecuencia (presencia de bandas) por locus en la totalidad de las cepas analizadas varió entre 0.052 y 0.875 , lo cual indica variabilidad genética entre los aislados (Figs. 4 y 5).
Del análisis de los perfiles de ADN obtenidos por ERIC-PCR usando una matriz de similitud y el método UPGMA, las 96 cepas de $G$. anatis se agruparon en 24 patrones indicando la existencia de variabilidad intraespecífica y por lo menos 24 cepas circulantes. Sin embargo, estos agrupamientos no se correlacionan con los biovares (Fig. 5), ni con la zona geográfica. 


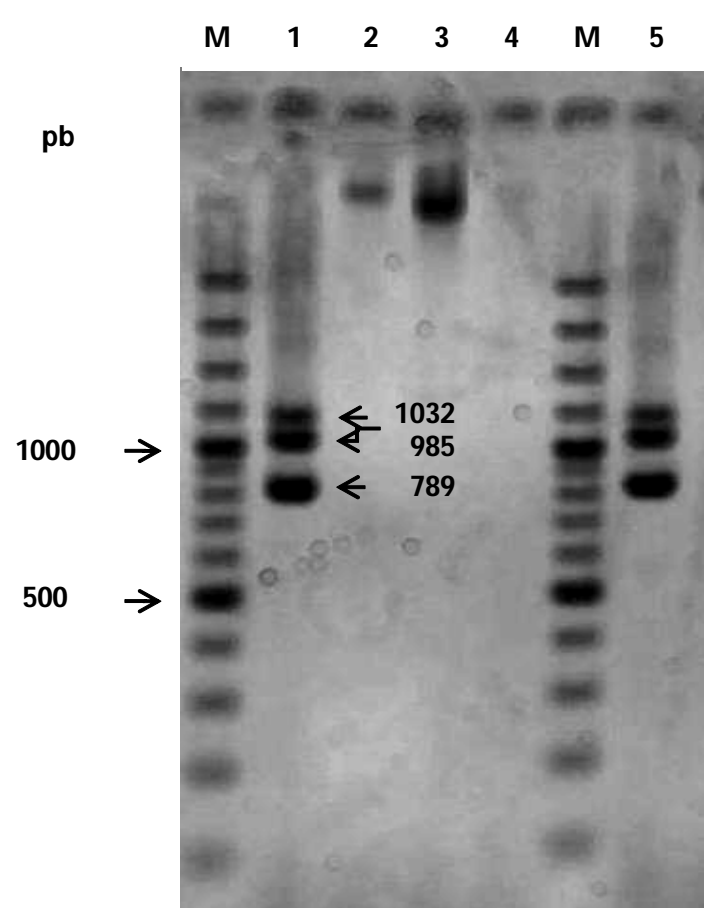

Figura 3. Perfiles de ADN específicos para Gallibacterium anatis y especies relacionadas obtenidos por PCR usando cebadores entre los genes ribosómicos 16S y 23S. Línea (especie): 1, Gallibacterium anatis ATCC 542; 2, Pasteurella multocida; 3, Ornithobacterium rhinotracheale; 4, Blanco de PCR; 5, G. anatis (aislado clínico); M, GeneRuler 100 bp Plus DNA Ladder (Fermentas, EEUU)

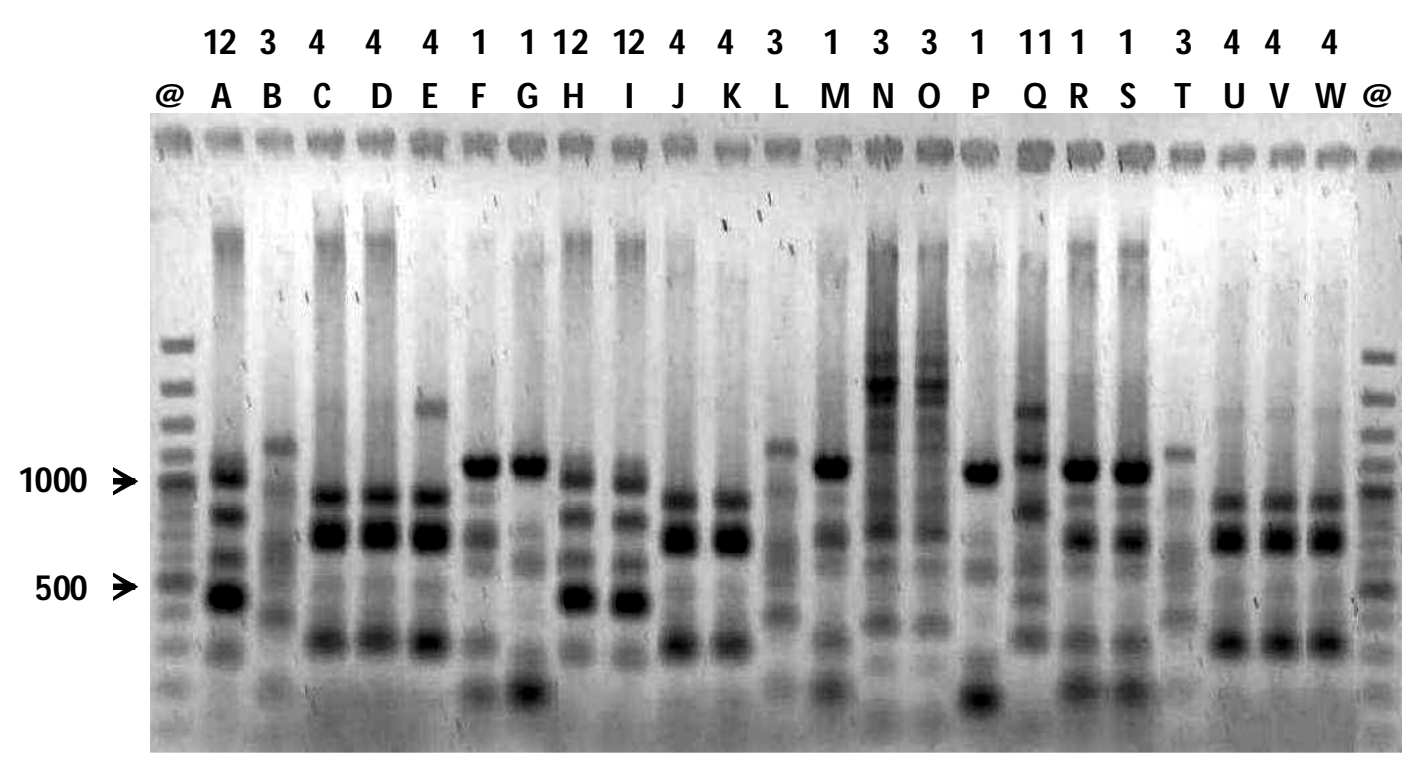

Figura 4. Perfiles de ADN obtenidos de cepas de Gallibacterium anatis, según biovar, obtenidos por ERIC-PCR. Líneas de A a W, cepas de G. anatis; @, marcador de peso molecular GeneRuler 100 bp Plus DNA Ladder. Los números indican el biovar que fue identificado 


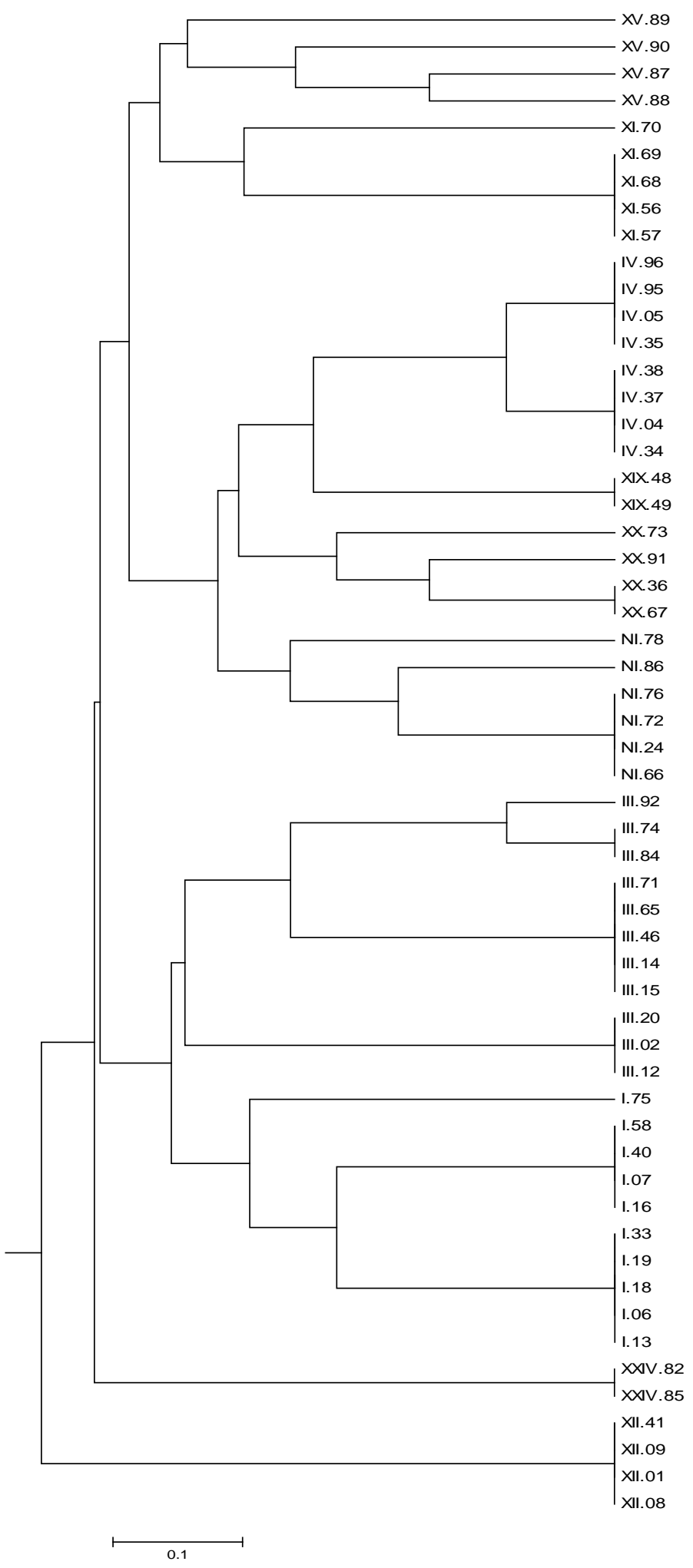

Figura 5. Dendrograma de similitud mostrando las relaciones entre las cepas de G. anatis obtenido del análisis de los patrones de ADN por ERIC-PCR (Huella genética de ADN) usando el método UPGMA. Los biovares y las cepas se indican con números romanos y arábigos, respectivamente 


\section{Discusión}

En Perú, la avicultura está siendo afectada por una serie de agentes patógenos que producen infecciones, entre ellas las respiratorias de diversa etiología, pero de parecida sintomatología, lo cual dificulta el diagnóstico clínico. Por otro lado, los microorganismos frecuentemente están en proceso de cambio, ya sea por mutaciones debido a su adaptación al medio en que se desarrollan o como consecuencia del intercambio de material genético entre los mismos. Estos cambios exigen el desarrollo y uso de metodologías alternativas a las convencionales que permitan identificar el agente infeccioso en forma oportuna.

Estudios de variabilidad genética de $G$. anatis han sido descritos en Dinamarca, Bélgica, Checoslovaquia y Alemania (Bojesen et al., 2003a,b,c; Bojesen y Shivaprasad, 2007; Bojesen et al., 2007; Christensen et al., 2003, 2004; Christensen y Bisgaard, 2010), donde se encuentran 24 biovares de G. anatis, y donde la subespecie haemolytica comprende los biovares 1-4, 6, 7, 10-24, la subespecie anatis el biovar $\mathrm{Pa}$, la genomoespecie 1 el biovar 5 y 8 , y la genomoespecie 2 el biovar 9. Asimismo, en estos trabajos se aislaron 37 cepas de $G$. anatis en diversas especies de aves, encontrándose los biovares $1,3,4,5,8,9,11,12$, $15,17,18,19,20,22,24$, Pa y Uc, siendo 15 de ellos, biovariedades hemolíticas, y $\mathrm{Pa}$ y Uc no hemolíticos. De estos dos últimos, $\mathrm{Pa}$ es el más frecuente, seguido de los biovares hemolíticos 1, 3, 4, 12 y 18 .

En el presente estudio se encontraron cepas de G. anatis hemolíticas correspondientes a los biovares 1, 3, 4, 11, 12, 15, 19, 20 y 24, y los más frecuentes fueron el 1, 3, 4 y NI. Estas diferencias podrían deberse a que en el trabajo de Bojensen et al. (2003b) se utilizaron cepas aisladas de más especies de aves y de diferentes países, dando posibilidad a encontrar mayor número de biovariedades. Además, el biovar NI indicaría que es un nuevo grupo de cepas circulan- tes, las cuales no han sido descritas y quizás sean únicas del Perú. No obstante, debido a las escasas investigaciones, no se puede indicar que estas cepas han estado en circulación o que son de evolución reciente.

Respecto a la sensibilidad antimicrobiana, Bojesen et al. (2003b, 2011) demostraron que cepas de G. anatis presentaban resistencia a $\geq 3$ antimicrobianos en el $65 \%$ de las cepas de campo; y solo dos cepas fueron sensibles a todos los antimicrobianos. Similar característica se observó en el presente estudio donde todas las cepas de G. anatis mostraron multirresistencia y tres fueron resistentes a todos los antimicrobianos estudiados. La resistencia a sulfamida $(98 \%)$ fue similar a las observaciones de Bojesen et al. (2011). La disminución a la sensibilidad antimicrobiana puede deberse al uso inadecuado de los antimicrobianos, lo cual constituye un riesgo para el control de la bacteria.

La variabilidad genética intraespecífica de G. anatis se realizó mediante ERIC-PCR. Esta es una técnica fácil y de bajo costo que genera perfiles de ADN reproducibles. Esta misma técnica fue utilizada por Leotta $e t$ al. (2006) para analizar 49 cepas de P. multocida de diferente origen, subespecie, biotipo, grupo capsular, serotipo somático y perfil de resistencia antimicrobiana. El método de tipificación ERIC-PCR es útil para distinguir los clones estrechamente relacionados, lo que permite el reconocimiento de los linajes clonales patógenos específicos. El método permite un análisis epidemiológico molecular fácilmente interpretable y puede servir como una herramienta para entender la naturaleza de G. anatis.

Bojesen et al. (2007) realizaron trabajos de variabilidad genética de cepas de $G$. anatis con el método AFLP (Polimorfismos en la longitud de fragmentos amplificados), donde reportaron $94 \%$ de similitud genética, en comparación con la observada en esta investigación que fue de 52 a $87 \%$. Esto demuestra una relativa heterogeneidad genética, así como diferencias en los biovares en ambas investigaciones. 


\section{Conclusiones}

- Se identificó G. anatis mediante técnicas bioquímicas y PCR usando cebadores específicos.

- Las cepas de G. anatis presentaron diversos perfiles de ADN mediante ERICPCR, encontrándose 10 biovares circulantes.

\section{Literatura Citada}

1. Bisgaard M, Christensen H, Bojesen AM, Christensen JP. 2005. Avian infections caused by species of Pasteurellaceae, an update. En: XIV World Veterinary Poultry Congress, Istanbul, Turkey.

2. Blackall PJ, Christensen H, Beckenham T, Blackall L, Bisgaard M. 2005. Reclassification of Pasteurella gallinarum, Haemophilus paragallinarum, Pasteurella avium and Pasteurella volantium as Avibacterium gallinarum comb. nov. Avibacterium avium comb. nov. and Avibacterium volantium comb. nov. Int J Syst Evol Microbiol 55: 353-362.

3. Bojesen A, Shivaprasad H. 2007. Genetic diversity of Gallibacterium isolates from California turkeys. Avian Pathol 36: 227-230.

4. Bojesen A, Christensen H, Nielsen O, Olsen J, Bisgaard M. 2003a. Detection of Gallibacterium spp in chickens by fluorescent 16S rRNA in situ hybridization. J Clin Microbiol 41: 5167-5172.

5. Bojesen AM, Torpdahl M, Christensen H, Olsen JE, Bisgaard M. $2003 b$. Genetic diversity of Gallibacterium anatis isolates from different chickens flocks. J Clin Microbiol 41: 2737-2740.

6. Bojesen AM, Nielsen SS, Bisgaard M. 2003c. Prevalence and transmission of haemolytic Gallibacterium species in chicken production systems with different biosecurity levels. Avian Pathol 32: 503-510.

7. Bojesen A, Nielsen O, Christensen J, Bisgaard M. 2004. In vivo studies of Gallibacterium anatis. Avian Pathol 33: 145-152.

8. Bojesen AM, Vásquez ME, Robles $F$, Gonzales C, Soriano EV, Olsen JE, Christensen H. 2007. Specific identification of Gallibacterium by PCR using primers targeting the 16S rRNA and 23S rRNA genes. Vet Microbiol 123: 262268.

9. Bojesen AM, Vasquez ME, Bager RJ. 2011. Antimicrobial susceptibility and tetracycline resistance determinant genotyping of Gallibacterium anatis. Vet Microbiol 148: 105-110.

10. Christensen H, Bisgaard M, Bojesen A, Mutters R, Elsen JE. 2003. Genetic relationships among avian isolates classified as Pasteurella haemolytica, «Actinobacillus salpingitidis» or Pasteurella anatis with proposal of Gallibacterium anatis gen. nov., comb. nov. and description of additional genomospecies within Gallibacterium gen. nov. Int J Syst Evol Microbiol 53: 275-287.

11. Christensen H, Bisgaard M. 2010. Molecular classification and its impact on diagnostics and understanding the phylogeny and epidemiology of selected members of Pasteurellaceae of veterinary importance. Berl Munch Tierarztl Wochenschr 123: 20-30.

12. Christensen H, Kuhnert P, Olsen JE, Bisgaard M. 2004. Comparative phylogenies of the housekeeping genes atpD, infB and rpoB ang the 16S rRNA gene within the Pasteurellaceae. Int $\mathrm{J}$ Syst Evol Microbiol 54: 1601-1609.

13. García BN. 2010. Caracterización fenotípica y genética de Pasteurella multocida. Tesis doctoral. Madrid: Universidad Complutense. $190 \mathrm{p}$.

14. García-Gómez E, Vaca S, PérezMéndez A, Ibarra-Caballero J, PérezMárquez V, Tenorio VR, NegreteAbascal E. 2005. Gallibacterium 
anatis-secreted metalloproteases degrade chicken IgG Avian Pathol 34: 426-429.

15. Kristensen BM, Frees D, Bojesen A. 2010. GtxA from Gallibacterium anatis, a cytolytic RTX-toxin with a novel domain organisation. Vet Res 41: 25.

16. Leon KP. 2009. Gallibacterium anatis. Avicultura Profesional 27(6): 24-26.

17. Leotta G, Chinen I, Vigo G, Gugliada J, Rivas M. 2006. Evaluación de dos técnicas para subtipificacion molecular para el estudio de Pasteurella multocida. Rev Arg Microbiol 38: 190-198.

18. [NCCLS] Comité Nacional de Normas de Laboratorio Cínico. 1993. Normas de funcionamiento de las pruebas de sen- sibilidad a los antimicrobianos de disco. Estándar aprobado. Documento NCCLS M2-A5 Wayne, Pa: Comité Nacional de Normas de Laboratorio Clínico.

19. Schliuter M. 2006. Analysis of multilocus fingerprinting data sets containing missing data. Mol Ecol Notes 6: 569-572.

20. Tamura K, Peterson D, Peterson N, Stecher G, Nei M, Kumar S. 2011. Molecular evolutionary genetics analysis using maximum likelihood, evolutionary distance, and maximum parsimony method. Mol Biol Evol 28: 2731-2739.

21. Vadillo S, Píriz S, Mateos E. 2002. Manual de microbiología veterinaria. Madrid: McGraw-Hill Interamericana. 853 p. 